\title{
Esporotricose felina no município de Bezerros, Agreste Pernambucano: Relato de caso
}

\author{
Adjanna Karla Leite Araujo ${ }^{*}$ \& Carlos Adriano de Santana Leal ${ }^{2}$ \\ ${ }^{1}$ Médica Veterinária Autônoma, Mestre em Ciências Veterinárias pela Universidade Estadual do Ceará e Centro \\ de Pesquisas Aggeu Magalhães - FIOCRUZ PE. Caruaru - Pernambuco, Brasil. \\ ${ }^{2}$ Doutorando em Ciência Animal Tropical pela Universidade Federal Rural de Pernambuco. Recife, Brasil \\ *Autor para correspondência: E-mail: adjanna_leite@hotmail.com
}

RESUMO. A esporotricose é uma doença crônica, cujo agente etiológico é um fungo do complexo Sporothrix, no entanto, apesar de ser uma zoonose, pouco se relata sobre a mesma na região nordeste do Brasil. Objetivou-se relatar um caso de esporotricose felina, na cidade de Bezerros, agreste de Pernambuco. Um felino de raça siamês, macho, castrado, com 5 anos e $4 \mathrm{~kg}$ de peso, apresentando histórico de múltiplas lesões cutâneas há 60 dias, foi atendido no Serviço de Dermatologia da Clínica Pelo \& Pele - Dermatologia Veterinária $^{\circledR}$. Foram observadas lesões ulceradas, crostas e nódulos distribuídos em várias regiões do corpo. Realizou-se punção com agulha fina e imprint das lesões para exame citopatológico. Por meio dos quais observou-se estruturas leveduriformes compatíveis com Sporothrix schenckii. O itraconazol na dose de $100 \mathrm{mg} /$ animal a cada 24 horas foi a droga escolhida para o tratamento, permanecendo por até 30 dias após cura clínica. Em três meses o animal apresentou cura das lesões, com repilação completa. Dessa forma, relata-se um caso de esporotricose felina em um animal procedente do município de Bezerros e recomenda-se aos profissionais veterinários que atuam nesta região, a inclusão da esporotricose como um diagnóstico diferencial em casos de dermatopatias ulcerativas, principalmente em felinos domésticos.

Palavras chave: Felino, micose, nordeste brasileiro, Sporothrix schenki

\section{Feline Sporotrichosis in Bezerros City, inland municipality of the state of Pernambuco, Brazil: Case report}

\begin{abstract}
Sporotrichosis is a chronic disease whose etiologic agent is a fungus from a Sporothrix schenckii complex, however, despite being a zoonosis, there are few cases reported in north-eastern Brazil. This study aimed to report a case of feline sporotrichosis in the city of Bezerros, Pernambuco. A Siamese cat, male, neutered, 5 years old and $4 \mathrm{~kg}$ weighting, with multiple skin lesions for 60 days long, was treated on Dermatology Service of Pelo \& Pele - Dermatologia Veterinária ${ }^{\circledR}$ clinic. Ulcerated lesions were observed, crusts and nodules distributed in many regions of the body. A fine needle aspiration and imprint of lesions for cytological examination was made. Whereby observed structures compatible with yeast Sporothrix schenckii. Itraconazole at a dose of 100mg/animal every 24 hours was the drug choice for treatment, staying for up to 30 days after clinical cure. In three months, the animal showed healing of the lesions, with complete regrowth. Thus, we report a case of feline sporotrichosis in an animal from Bezerros City and is recommended to veterinary professionals working in this region, the inclusion of sporotrichosis as a differential diagnosis in cases of ulcerative skin diseases, mainly in domestic cats.
\end{abstract}

Keywords: Feline, mycosis, Brazil's northeast, Sporothrix schenkii 


\section{Introdução}

A esporotricose é uma doença crônica cujo agente etiológico é um fungo do complexo Sporothrix. Foi descrita primeiramente em 1898 nos EUA por Benjamin Schenck (Barros et al., 2010). Segundo Cruz (2010), o S. schenckii cresce no solo, troncos, espinhos e vegetações em decomposição. É um fungo dimórfico, apresentando-se na forma micelial nas temperaturas de $25^{\circ} \mathrm{C}$ a $30^{\circ} \mathrm{C}$ e leveduriforme à $37^{\circ} \mathrm{C}$ (Medleau et al., 2003). Tem distribuição mundial, prevalecendo nos EUA, porém com maior importância epidemiológica no México e no Brasil (Larsson, 2011).

Avanços da biologia molecular e nas pesquisas em micologia mostraram que a espécie $S$. Schenckii, na verdade é um complexo de espécies, composto por S. schenckii, S. brasiliensis, $S$. globosa, S. mexicana, S. luriae e S. albicans (Cruz, 2013).

A esporotricose é uma zoonose relacionada aos profissionais, como jardineiros, horticultores e agricultores. É considerada uma ergodermatose, pelo seu caráter zoonótico ocupacional entre os profissionais da área de Veterinária (MarquesMelo et al., 2014).

Nos gatos, a transmissão se dá pelos confrontos, entre machos intactos em idades reprodutivas, com livre acesso à rua, disputando territórios e fêmeas. Neste momento se um deles for portador do fungo nas unhas (hábito de cavar ou afiar as unhas em troncos), ou se já apresentar lesões infectadas pelo agente, infectará o outro animal (Meinerz et al., 2010). A esporotricose é transmitida para os humanos pelas arranhaduras ou mordeduras de animais infectados e, de forma rara por via respiratória (Marques et al., 1993). Relatos de esporotricose têm sido descritos nas regiões Sul e Sudeste do Brasil (Otsuka et al., 2004, Madrid et al., 2010). No entanto, segundo Filgueira (2009), poucos casos foram relatados no nordeste brasileiro.

Devido à escassez de estudos que descrevam casos da doença na região nordeste e por tratar-se de uma zoonose, objetivou-se relatar um caso de esporotricose felina, na cidade de Bezerros, Pernambuco, Brasil.

\section{Relato de caso}

No dia 11 de setembro de 2015 foi encaminhado para atendimento no Serviço de Dermatologia da Clínica Pelo \& Pele -
Dermatologia Veterinária ${ }^{\circledR}$, localizada na cidade de Caruaru, interior do Pernambuco, um felino de raça siamês, macho, castrado, com idade de 5 anos e $4 \mathrm{~kg}$ de peso, não vacinado, com queixa principal de múltiplas lesões cutâneas há 60 dias. O animal procedia do município de Bezerros, localizado no agreste do estado de Pernambuco, onde vivia em residência de ambiente urbano e semidomiciliado. Segundo o responsável pelo animal, o quadro iniciou-se com formação de nódulos localizados em pavilhão auricular. Relatou também normofagia, normodipsia, normoúria e normoquezia. Observou-se mucosas levemente hipocoradas, leve desidratação, auscultação e palpação sem alterações, e temperatura de $39,1{ }^{\circ} \mathrm{C}$.

$\mathrm{Na}$ avaliação dermatológica foram observadas lesões cutâneas em gomas ulceradas e crostas (Figura 1.A), nódulos distribuídos nas regiões da cabeça, pavilhão auricular (Figura 1.B) e membros torácicos (Figura 1.C).

Os responsáveis não apresentavam lesões aparentes e não havia outros animais na residência. Foi realizada punção com agulha fina (PAAF) e imprint das lesões para exame citopatológico. O material coletado foi posto em lâminas de vidro e corado pelo método de Romanowsky. Sendo observadas inúmeras estruturas leveduriformes compatíveis com fungos do complexo Sporothrix schenckii (Figura 2). Logo após a coleta de amostras, o paciente foi deslocado para a sala de observação para proceder com a assepsia adequada das lesões com clorexidine a $1 \%$ (Sept Clean ${ }^{\circledR}$ ) debridamento de algumas das lesões que já possuíam material necrótico.

Para o tratamento foi prescrito cefalexina $\left(\right.$ PetSporim $^{\circledR}$ ) na dose de $30 \mathrm{mg} / \mathrm{kg}$ a cada 12 horas, durante 21 dias, solução spray de gentamicina, miconazol e valerato de betametasona (Dermotrat ${ }^{\circledR}$ ) a cada 24 horas, sobre a lesão, durante 14 dias e itraconazol (Sporanox ${ }^{\circledR}$ ) na dose de $50 \mathrm{mg}$ por dia, durante 4 meses, além do isolamento do animal.

No dia 29 de setembro, o felino foi trazido ao consultório apresentando uma melhora aparente do quadro. No dia 21 de outubro, retornou ao consultório apresentando grande debilidade, mucosas ictéricas, anorexia e caquexia, porém o quadro dermatológico continuava evoluindo positivamente. Como o animal apresentava-se clinicamente debilitado, descontinuou-se o itraconazol, evitando assim uma sobrecarga da medicação no organismo do animal. No entanto, 
foi prescrita dieta comercial com teor protéico elevado (Recovery Royal Canin ${ }^{\circledR}$ ) na tentativa de

sair da inapetência e promover a recuperação.
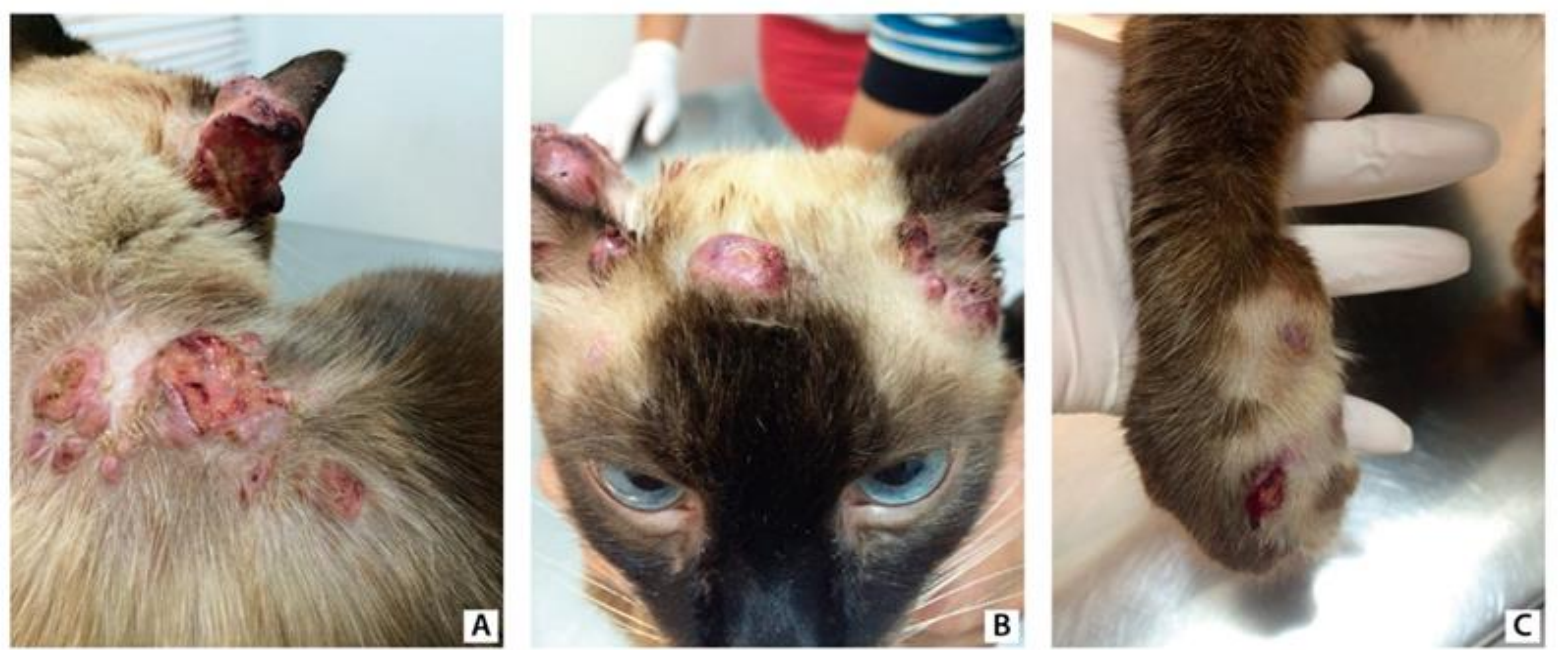

Figura 1.A. Lesão em gomas ulceradas; 1.B. Lesão nodular em região de cabeça e pavilhão auricular; 1.C. Lesão em membro torácico.

No dia 18 de novembro, em novo retorno, observou-se uma melhora no estado geral, no entanto, as lesões cutâneas agravaram-se e, com isso foi retomado o tratamento com itraconazol na dose de $100 \mathrm{mg} /$ dia por até 30 dias após cura clínica, uma vez que houve uma recuperação do estado geral.

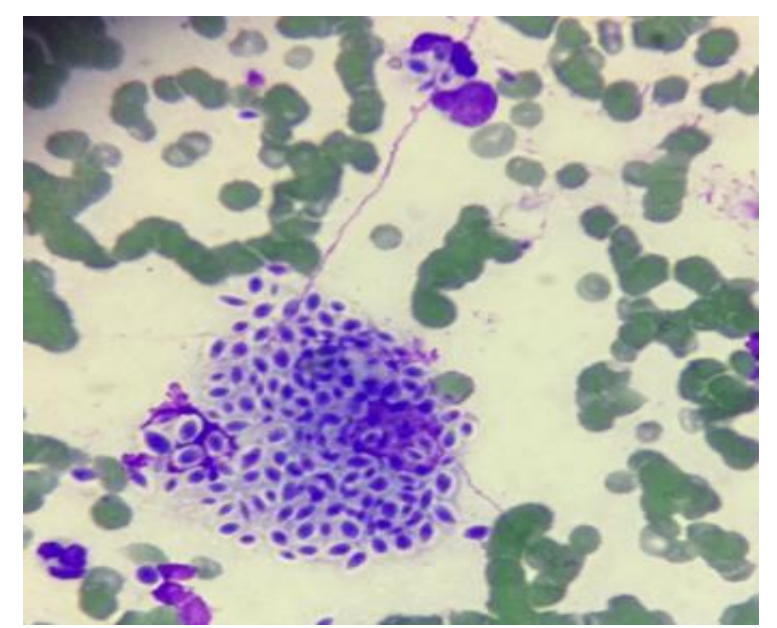

Figura 2. Células leveduriformes características de agentes do complexo Sporothrix schenckii.

$\mathrm{O}$ animal continuou o tratamento sem intercorrências e após três meses com a nova dosagem, apresentou remissão das lesões cutâneas com cicatrização (Figura 3.A) e repilação total das regiões afetadas (Figura 3.B).

Manteve-se, no entanto, o tratamento por mais 30 dias, após a total recuperação das lesões cutâneas. E ao final de todo o tratamento, o felino foi considerado curado.

\section{Discussão}

As doenças fúngicas representam a segunda dermatose mais frequente dos felinos e devem ser analisadas como prováveis diagnósticos quando o felino apresenta úlceras como lesões (Larsson et al., 1996). Segundo Gremião et al. (2006), o quadro clínico apresentado por gatos esporotricóticos vai desde infecções subclínicas, passando por lesão única até lesões múltiplas e sistêmicas. $\mathrm{O}$ gato do relato apresentou inicialmente lesão única evoluindo para inúmeras lesões ulceradas e abscedadas em regiões da cabeça, pavilhão auricular, membros torácicos e região dorsal.

É importante excluir outras afecções granulomatosas, como: infecções bacterianas, micobacterioses atípicas, neoplasias, síndrome lepróide felina, leishmaniose, doenças alérgicas, autoimunes e outras infecções fúngicas como a criptococose e a histoplamose, pois todas essas afecções mimetizam um quadro úlcerogranulomatoso (Rocha, 2014).

No felino do caso em relato, para se estabelecer um diagnóstico, foram realizados exames citopatológicos pela punção por agulha fina e pela técnica de imprint, baseado no estudo de Cagnini et al. (2012) no qual citam a PAAF como uma técnica menos invasiva e bastante segura, obtendo resultados iguais ou superiores ao exame histopatológico na identificação do agente, além de ser prático e rápido para a rotina clínica e possuir um baixo custo no investimento. $\mathrm{O}$ exame 
citológico para os felinos é muito útil, pois esta espécie, mais do que outras, apresenta uma elevada carga parasitária na maioria das lesões cutâneas, o que torna esta técnica muito eficiente para o diagnóstico da enfermidade na espécie (Cruz, 2010).
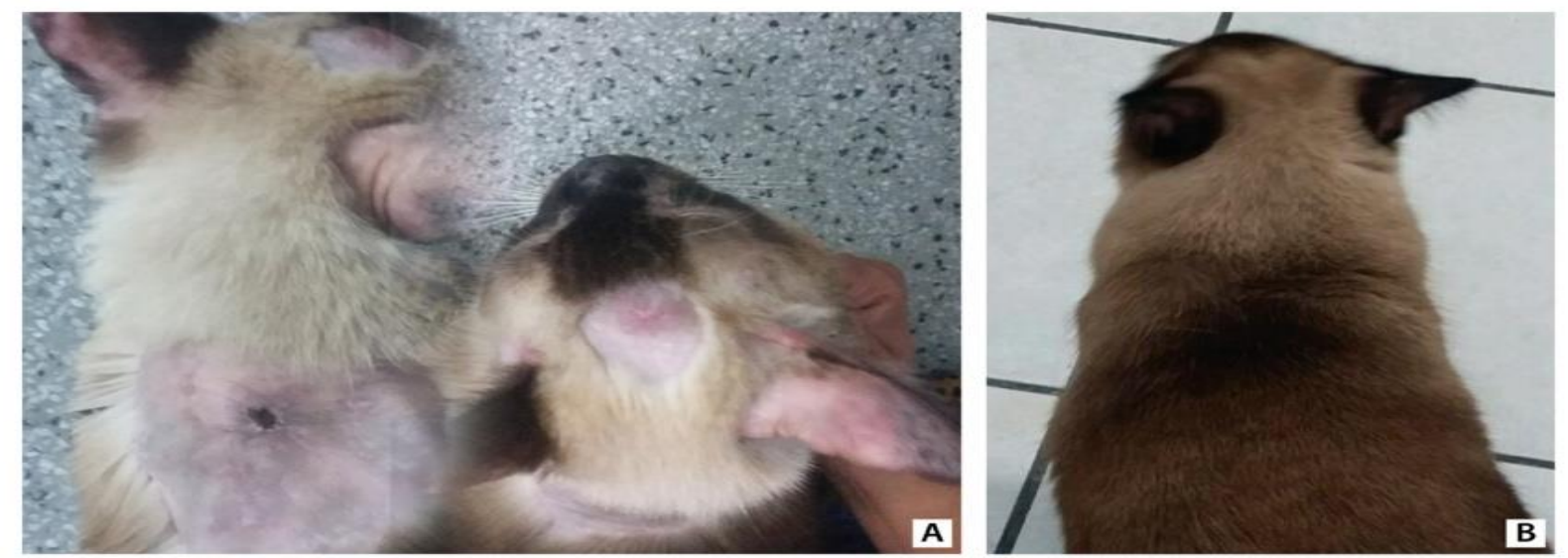

Figura 3.A. Cicatrização das lesões; 3.B. Depilação das regiões afetadas.

O antifúngico de eleição para o tratamento da esporotricose em felinos é o itraconazol devido a sua efetividade e segurança, tornando-o superior quando comparado aos outros fármacos de ação antifúgicas (Pereira et al., 2010).

A dose do itraconazol para felinos varia de 5 a $10 \mathrm{mg} / \mathrm{kg}$ uma ou duas vezes ao dia; no entanto, Pereira et al. (2010) afirmam que a dose do itraconazol pode variar de 30 a $100 \mathrm{mg} / \mathrm{kg}$ uma a duas vezes ao dia. Para o tratamento do felino em questão, foi utilizado, inicialmente itraconazol na dose de 50mg uma vez ao dia, e apesar de observarmos uma melhora no quadro dermatológico, o animal apresentou debilidade e anorexia. Após a recuperação do estado geral adotou-se a dose referida por Rocha (2014) em seu trabalho, de $100 \mathrm{mg}$ uma vez ao dia. O tempo de tratamento foi baseado nos estudos de Larsson (2011), mantendo o itraconazol por mais 4 semanas após a remissão do quadro lesional, o que totalizou 4 meses de tratamento.

Casos vêm sendo relatados em vários lugares do país, como surtos no Rio Grande do Sul (Kersting et al., 2014) e em Minas Gerais (Barros et al., 2012). Todavia, mesmo com alguns já relatados no nordeste brasileiro, Rio Grande do Norte (Filgueira, 2009), Paraíba (Nunes et al., 2013) e Alagoas (Marques-Melo et al., 2014), a esporotricose, e principalmente a felina, ainda é um assunto pouco explorado nesta região, porém, se não for dada a devida importância a esta zoonose, corremos o risco de nos tornarmos área endêmica por falta de conhecimento.

\section{Conclusão}

Relata-se um caso de esporotricose felina em um animal procedente do município de Bezerros, estado de Pernambuco, região nordeste do Brasil. Recomenda-se aos profissionais veterinários que atuam nesta região, a inclusão da esporotricose como um diagnóstico diferencial em casos de dermatopatias ulcerativas, principalmente em felinos domésticos.

\section{Referências Bibliográficas}

Barros, M. B. L., Schubach, T. P., Coll, J. O., Gremião, I. D., Wanke, B. \& Schubach, A. (2010). Esporotricose: a evolução e os desafios de uma epidemia. Revista Panamericana de Salud Publica, 27, 455-460.

Barros, M. S., Ferrari, H. J., Rezende, R. S. \& Faria, J. L. M. (2012). Esporotricose felina: primeiro relato de caso diagnosticado em Uberaba-Minais Gerais. Veterinária Notícias, 18, 110-120.

Cagnini, D. Q., Rodrigues, M. M. P., Palumbo, M. I. P., Heckler, M. C. T., Peixoto, A. S., Amorim, R. L. \& Machado, L. H. A. (2012). Diagnóstico citológico e tratamento da esporotricose felina: relato de caso. Veterinária e Zootecnia, 19, 186-191.

Cruz, L. C. H. (2010). Micologia veterinária. Revinter, Rio de Janeiro.

Cruz, L. C. H. (2013). Complexo Sporothrix schenckii. Revisão de parte da literatura e considerações sobre o diagnóstico e a 
epidemiologia. Veterinária e Zootecnia, 20, 828.

Filgueira, K. D. (2009). Esporotricose na espécie canina: relato de um caso na cidade de Mossoró-RN. Ciência Animal Brasileira, 10, 673-677.

Kersting, A.B., Rolim, V.M., Hesse, K., Ferreiro, L., Da Costa, F.V.A., Sonne, L., Driemeier, D. (2014). Descrição de um surto de esporotricose felina com o acometimento humano no litoral norte do Rio Grande do Sul. VII Encontro Nacional de Diagnóstico Veterinário.

Gremião, I. D. F., Pereira, S. A., Rodrigues, A. M., Figueiredo, F. B., Nascimento Jr, A., Santos, I. \& Schubach, T. M. P. (2006). Tratamento cirúrgico associado à terapia antifúngica convencional na esporotricose felina. Acta Science Veteterinária, 34, 221-223.

Larsson, C. E. (2011). Esporotricose. Brazilian Journal of Veterinary Research and Animal Science, 48, 250-259.

Larsson, C. E., Otsuka, M. \& Michalany, N. S. (1996). El gato como fuente de infección en la esporotricosis humana: relato de casos en São Paulo (Brasil). Congresso Panamericano de Ciências Veterinárias. Campo Grande.

Madrid, I. M., Mattei, A., Martins, A., Nobre, M. $\&$ Meireles, M. (2010). Feline sporotrichosis in the Southern region of Rio Grande do Sul, Brazil: clinical, zoonotic and therapeutic aspects. Zoonoses and Public Health, 57, 151154.

Marques-Melo, E. H., Lessa, D. F. d. S., Garrido, L. H. A., Nunes, A. C. B. T., Chaves, K. P., Porto, W. J. N. \& Notomi, M. (2014). Felino doméstico como agente transmissor de esporotricose para humano: relato do primeiro caso no estado de Alagoas. Revista Baiana de Saúde Pública, 38, 490-498.

Marques, S. A., Franco, S. R., Camargo, R. M., Dias, L. D. F., Júnior, H. \& Fabris, V. E. (1993). Esporotricose do gato doméstico (Felis catus): transmissão humana. Revista do instituto de Medicina tropical de São Paulo, 35, 327-330.
Medleau, L., Hnilica, K. A. \& Fagliari, G. S. (2003). Dermatologia de pequenos animais: atlas colorido e guia terapêutico. Roca, São Paulo.

Meinerz, A. R. M., Ávila Antunes, T., Souza, L. L., Silva Nascente, P., de Faria, R. O., Cleff, M. B., Gomes, F. R., Oliveira Nobre, M., Reischak, D. \& Schuch, L. F. D. (2010). Frequência do virus da leucemia felina (VLFe) em felinos domésticos (Felis catus) semidomiciliados nos municípios de Pelotas e Rio Grande. Ciência Animal Brasileira, 11, 9093.

Nunes, G. D. L., Santos, R. C., Filgueira, K. D., Filgueira, F. G. F. \& Fernandes, T. H. T. (2013). Esporotricose felina no município de Itaporanga, estado da Paraíba, Brasil: relato de um caso. Arquivos de Ciências Veterinárias e Zoologia da UNIPAR, 14, 157-161.

Otsuka, M., Castro, R. C. C., Michalany, N. S., Lucas, R., Larsson Júnior, C. E. \& Larsson, C. E. (2004). Sporotrichosis in São Paulo (Brazil): clinical and epidemiological features. Veterinary Dermatology, 15, 46-46.

Pereira, S. A., Passos, S. R. L., Silva, J. N., Gremião, I. D. F., Figueiredo, F. B., Teixeira, J. L., Monteiro, P. C. F. \& Schubach, T. M. P. (2010). Response to azolic antifungal agents for treating feline sporotrichosis. The Veterinary Record, 166, 290-294.

Rocha, R. F. D. B. (2014). Tratamento da esporotricose felina refratária com a associação de iodeto de potássio e itraconazol oral, Rio de Janeiro.

\section{Article History}

Received 29 August 2016

Accepted 14 September 2016

Available on line 14 October 2016

License information: This is an open-access article distributed under the terms of the Creative Commons Attribution License 4.0, which permits unrestricted use, distribution, and reproduction in any medium, provided the original work is properly cited. 